Bartın Üniversitesi

Eğitim Fakültesi Dergisi

Cilt 6, Sayı 3, s. 1420-1429, Ekim 2017

BARTIN - TÜRKIYE

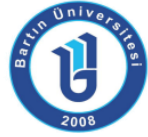

ISSN: 1308-7177
Bartin University

Journal of Faculty of Education

Volume 6, Issue 3, p. 1420-1429, October 2017

BARTIN - TURKEY

Doi: $10.14686 /$ buefad.346494

\title{
Öğretmen Adaylarının Benimsedikleri Eğitim Felsefeleri ile Başarı Motivasyonları Arasındaki illişkiler
}

Emrullah YILMAZ, Yrd. Doç. Dr., Bartın Üniversitesi Eğitim Fakültesi, emrullahyilmaz@bartin.edu.tr, ORCID: http://orcid.org/0000-0003-2346-9939

Öz: Bu çalışmanın amacı öğretmen adaylarının benimsedikleri eğitim felsefeleri ile sahip oldukları başarı motivasyonları arasındaki ilişkinin araştııılmasıdır. Bu amaçla, 2016 yılında Türkiye'de iki üniversite tarafından verilen pedagojik formasyon kursuna devam eden 570 katılımcıya eğitim-öğretim felsefesini belirleme ölçeği ve başarı odaklı motivasyon belirleme ölçeği uygulanmıştır. SPSS 22 istatistik programı kullanılarak yapılan analizlere göre öğretmen adaylarının başarı motivasyonu ile benimsedikleri eğitim felsefeleri arasında orta düzeyde, pozitif ve anlamlı bir ilişki tespit edilmiştir. Başarı motivasyonu genel değişkeni ile en yüksek ilişkiye sahip olan eğitim felsefesi ilerlemecilik iken, ilerlemeciliği yeniden kurmacılık, daimicilik ve esasicilik takip etmektedir. Standartlaştırılmış katsayılara göre başarı odaklı motivasyon üzerinde en yüksek etkiye sahip olan değişkenler sırasıyla ilerlemecilik, daimicilik, yeniden kurmacılık ve esasicilik şeklinde sıralanmıştır. Modern eğitim felsefelerinin klasik olanlara kıyasla başarı motivasyonu ile daha yakından ilişkili oldukları gözlenmiştir.

Anahtar Kelimeler: eğitim felsefesi, başarı motivasyonu, yordama, ilişki

\section{Relationships between Educational Philosophies Favoured by Prospective Teachers and Their Achievement Motivation}

Abstract: The aim of this study is to examine the relationship between educational philosophies favoured by prospective teachers and their achievement motivation. To this end, educational philosophies determination scale and achievement focused motivation scale were applied to 570 subjects attending pedagogical formation courses provided by two universities in Turkey in 2016. In the light of the analyses carried out in SPSS 22 statistical package programme, a medium level, positive, significant correlation was found between prospective teachers' achievement motivation and philosophies of education they favour. The educational philosophy having the highest correlation with achievement motivation was progressivism followed by reconstructionism, perennialism and essentialism, respectively. As the standardised coefficients suggest, the variable with the highest effect on achievement motivation was progressivism followed by perennialism, reconstructionism and essentialism, respectively. It was observed that contemporary philosophies of education more closely correlated with achievement motivation compared to the classical ones.

Key Words: educational philosophy, achievement motivation, prediction, relationship 


\section{GíRiş}

Felsefe eğitimin teorisi olarak düşünülebilir (Akpınar, 2010). Bu düşünceye göre eğitim felsefenin uygulanması ve planlı bir şekilde gerçekleşmesi olarak ifade edilebilir (Ayhan, 1997). Felsefe eğitim-öğretim sürecinde özellikle hedeflerin belirlenmesinde önemli rol oynaması bakımından dikkate alınması gereken bir alandır. Varlık felsefesi (ontoloji), bilgi felsefesi (epistemoloji) ve değerler felsefesi (aksiyoloji) eğitim-öğretim süreçlerinde yol gösterici bir işleve sahiptir. Ancak, eğitim sürecinde etkileri daha yoğun olarak görülen başlıca felsefi akımlar idealizm, realizm, pragmatizm, natüralizm ve varoluşçuluk olarak sıralanabilir. Felsefenin günümüz dünyasında önemini hissettiren dallarından biri de eğitim felsefesidir (Sönmez, 2009). Eğitim felsefesi eğitim üzerine düşünmek (Duman, 2008), kafa yormak olarak tarif edilebilir. Biçer, Er ve Özel (2013) ise eğitim felsefesini "eğitim politikalarına ve uygulamalarına yön veren varsayım, inanç, karar ve ölçütleri inceleyen, tutarlılık ve anlam yönünden kontrol eden bir disiplin veya sistemli fikir ve kavramlar bütünü" olarak tarif etmektedir. Eğitim-öğretim felsefeleri, eğitim uygulamalarına öncülük eder ve bu uygulamaları etkiler (Semerci, Semerci ve Yılmaz, 2106). Youngs (1979) felsefenin "eğitim anlayışımızı aydınlatması ve eylemlerimiz için temel teşkil etmesi" gerektiğini belirterek, alınan kararların, yapılan eylemlerin bir felsefeye dayandırıması ve felsefenin kararlar ve eylemlerin gerekçesi olarak kullanılmasının gerektiğini, eğitim felsefesinin temel işlevinin de bu olduğunu ifade etmiştir. Eğitim felsefeleri daimicilik, esasicilik, ilerlemecilik ve yeniden kurmacılık olarak sıralanabilir.

En eski ve en tutucu eğitim felsefesi olarak da nitelenebilecek olan daimicilik, temelde realizme dayanmakla birlikte idealizme de yakın kabul edilebilir (Akpınar, 2010). Daimicilerin en temel görüşü insan doğasının ve dünyanın değişmez ve sürekli olduğudur (Kaplan ve Owings, 2015). Her yer ve durumda geçerli olan, evrensel bir eğitim anlayışına sahiptir bu nedenle bireysel farklılıkları dikkate almaz. Esasicilik de daimicilik gibi idealizm ve realizme yakındır ancak doğrudan bir eğitim anlayışı olarak ortaya çıkmıştır. Esasicilere göre eğitim hayata hazırlıktır ve eğitimde zorlama ve disiplin vardır (Akpınar, 2010). Geçmişten gelen birikim ve değerlerin yeni nesile öğretilmesi gerektiğini savunmaktadırlar. Daimicilik ve esasiciliğe göre daha modern yaklaşıma sahip olan ilerlemecilik zamanın değişmesi ve dünyanın evrilmesiyle birlikte eğitimin aynı yaklaşımları sergilememesi ve kendisini değişime adapte etmesi gerektiği düşüncesini savunmaktadır (Sahu, 2002). Pragmatist felsefeye yakın olan ilerlemecilere göre eğitim hayata hazırlık değil, hayatın kendisidir. Öğrenci öğrenme sürecinde aktif olmalı ve öğretmen otoriteden ziyade bir rehber olmalıdır. Geçmişin değer ve olgularına vurgu yapan daimici ve esasici yaklaşımlara karşı çıkan yeniden kurmacılık öğrencinin eğitim sürecinin merkezinde olması gerektiğini savunur (Moss ve Lee, 2010). Yeniden kurmacılara göre eğitimin amacı toplumu yeniden yapılandırmak, yeni bir toplum düzeni kurmak ve gerçek demokrasiyi gerçekleştirmektir (Akpınar, 2010). Bireyin özgürlüğü esastır. Bu öğrenci merkezli felsefede öğretmenin işlevi öğrencilerin problem çözme ve hayat boyu öğrenme becerilerini geliştirmelerine yardımcı olmaktır (Conti, 2007). Eğitim felsefeleri arasında daimicilik ve esasicilik klasik; ilerlemecilik ve yeniden kurmacılık ise modern eğitim yaklaşımlarına sahip olmalarıyla bilinmektedir.

Motivasyon kavramı eğitim, özellikle de eğitim psikolojisi alanında sıklıkla karşılaştığımız kavramlardan biridir. Bunun nedeninin, bu kavramın tanımında yer alan "motivasyon, davranışı başlatan, yönlendiren ve sürdüren içsel bir durumdur" (Woolfolk, 2013, 431) ifadesinde de değinildiği gibi motivasyonun insan davranışları üzerindeki ciddi etkisi olduğu söylenebilir. Motivasyon doğrudan gözlemlenemeyen, varlığı hakkında sergilenen davranışlara bakılarak çıkarımlar yapılabilen, soyut bir kavramdır. 
Akademik başarı genellikle öğretim sürecinde en sık hedeflenen bağımlı değişkenlerden biridir (Yılmaz, 2014). Birçok çalışmada farklı bağımsız değişkenlerin akademik başarı üzerindeki etkisi araştırılmıştır. Bu bağımsız değişkenlerden biri de motivasyondur. Başarının motivasyona ya da bazı araştırmacıların iddia ettiği gibi motivasyonun başarıya yol açtığı düşünülmektedir (Curwin, 2014) ve başarı ve motivasyon birbirini etkilemektedir (Guthrie, Wigfield ve VonSecker, 2000). Bu nedenle başarı ve motivasyon kavramlarını bir araya getiren başarı motivasyonu ya da başarı güdüsü kavramı önem kazanmaktadır. Başarı motivasyonu eğitim ve öğrenme açısından üzerinde önemle durulması gereken kavramlardan biridir (Schunk, 2012). Başarı motivasyonu da motivasyon gibi çok yönlü ve karmaşık bir kavramdır (Story ve diğ. 2009). "Başarı güdüsü bireyin standardı belirlenmiş hedeflere ulaşmak için tüm zamanını ve enerjisini kullanmasına işaret eder" (Ülgen, 1997, s.65). Kaur (2013) ise başarı motivasyonunu "başarı veya arzu edilen bir amaca ulaşmak için çaba gösterme eğilimi" olarak tanımlamaktadır.

Literatürde eğitim felsefeleri ile başarı güdüsü arasındaki ilişkiyi inceleyen çalışmaya rastlanmamıştır. Bu çalışma literatürdeki bu boşluğu doldurma amacı taşımakta ve bu iki önemli kavram arasındaki ilişkilere dikkat çekmeyi de hedeflemektedir.

\section{YÖNTEM}

Araştırma ilişkisel tarama modeliyle yürütülmüştür. Araştırmanın örneklemini 2016 yılında iki üniversitede aynı zaman diliminde verilen pedagojik formasyon kursuna devam eden, çoğunluğu lisans son sınıf öğrencisi olmak üzere lisans mezunlarının da yer aldığı 570 öğrenci oluşturmuştur. Araştırmada iki ölçekten yararlanılmıştır. Birinci ölçek Semerci, Semerci ve Çerçi tarafından 2002 yılında geliştirilen eğitim-öğretim felsefesini belirleme ölçeğidir. Beşli likert ölçek olarak yapılandırılan ölçekte maddelere yapılan değerlendirmeler "Kesinlikle reddediyorum: 1" ifadesi ile "Tamamen katılıyorum: 5" ifadesi arasında derecelendirilmiştir. Ölçeğin, KMO genel değeri 0.77, Bartlett testi değeri 1295.055 ve Cronbach Alpha katsayısı 0.73'tür. Ölçekte, 10 madde daimicilik, 12 madde esasicilik, 13 madde ilerlemecilik ve 12 madde yeniden kurmacılık ile ilgili olmak üzere toplamda 47 madde bulunmaktadır.

Araştırmada kullanılan ikinci ölçek, Semerci tarafından 2010 yılında geliştirilen Başarı Odaklı Motivasyon (BOM) ölçeğidir ve geliştirilme sürecinde 827 katılımcıya uygulanmıştır. Uygulama, Fırat Üniversitesi (Elazığ), Cumhuriyet Üniversitesi (Sivas), Atatürk Üniversitesi (Erzurum), Yüzüncü Yıl Üniversitesi (Van) ve Muş Alparslan Üniversitesinde yapılmıştır. Ölçeğin oluşturulması sürecinde faktör analiziyle ilgili işlemlerde dış etkiler, iç etkiler, hedef büyütme ve öz-bilinç olmak üzere dört faktörlü bir yapı ortaya çıkmıştır. Yapılan faktör analizi sonucunda toplam varyansın yüzde 37.910'unun karşılandığı görülmektedir. Madde toplam korelasyonları 0.36 ile 0.58 arasında değerler almıştır. Çalışmada, 49 veri çiftlemesi yapılmıştır ve test tekrar test korelasyonu $0.977(\mathrm{p}<0.01)$ bulunmuştur. Katılımcıların iki yarıdan aldıkları puanlar arasındaki korelasyon $0.895(\mathrm{p}<0.01)$ bulunmuştur. Çalışmada, Cronbach Alpha katsayısı 0.896 bulunmuştur (Semerci, 2010). Çalışmadan elde edilen veriler SPSS 22 istatistik programı yoluyla analiz edilmiş ve yorumlanmıştır.

\section{BULGULAR}

Çalışmadan elde edilen veriler ışığında oluşturulan korelasyon tabloları, bağımsız değişkenin (eğitim felsefeleri) bağımlı değişkeni (başarı motivasyonu) yordama düzeyi, frekans dağılım histogramı ve saçılma grafiği ve bu verilere ilişkin yorumlar aşağıda verilmiştir. Öncelikle, eğitim felsefeleri ve başarı motivasyonu arasındaki korelasyon değerleri ve anlamlılık düzeyi aşağıda, Tablo 1'de verilmiştir. 
Tablo 1

Eğitim Felsefeleri ve Başarı Motivasyonu Arasındaki Korelasyonlar

\begin{tabular}{|c|c|c|c|c|c|c|c|}
\hline & & EFgenel & EFdai & EFesa & EFiler & EFykur & BOMgenel \\
\hline \multirow{3}{*}{ EFgenel } & Pearson Korelasyonu & 1 & $611^{* *}$ &, $603^{* *}$ &, $575^{* *}$ & $719^{* *}$ &, $362^{* *}$ \\
\hline & $\mathrm{p}$ & & ,000 & ,000 & ,000 & ,000 & ,000 \\
\hline & $\mathrm{N}$ & 570 & 570 & 570 & 570 & 570 & 570 \\
\hline \multirow{3}{*}{ EFdai } & Pearson Korelasyonu & $611^{* *}$ & 1 &, $572^{* *}$ & ,006 & $121^{* *}$ & $132^{* *}$ \\
\hline & $\mathrm{p}$ & ,000 & & ,000 & ,885 & ,004 & ,002 \\
\hline & $\mathrm{N}$ & 570 & 570 & 570 & 570 & 570 & 570 \\
\hline \multirow{3}{*}{ EFesa } & Pearson Korelasyonu &, $603^{* *}$ &, $572^{* *}$ & 1 &,$- 135^{* *}$ & $134^{* *}$ & 021 \\
\hline & $\mathrm{p}$ & ,000 & ,000 & & ,001 & ,001 & ,620 \\
\hline & $\mathrm{N}$ & 570 & 570 & 570 & 570 & 570 & 570 \\
\hline \multirow{3}{*}{ EFiler } & Pearson Korelasyonu &, $575^{* *}$ & ,006 &,$- 135^{* *}$ & 1 & $642^{* *}$ & $431^{* *}$ \\
\hline & $\mathrm{p}$ & ,000 & ,885 & ,001 & & ,000 & ,000 \\
\hline & $\mathrm{N}$ & 570 & 570 & 570 & 570 & 570 & 570 \\
\hline \multirow{3}{*}{ EFykur } & Pearson Korelasyonu & $719^{* *}$ & $121^{* *}$ & $134^{* *}$ & $642^{* *}$ & 1 & $359^{* *}$ \\
\hline & $\mathrm{p}$ & ,000 & ,004 & ,001 &, 000 & & ,000 \\
\hline & $\mathrm{N}$ & 570 & 570 & 570 & 570 & 570 & 570 \\
\hline \multirow{3}{*}{ BOMgenel } & Pearson Korelasyonu &, $362^{* *}$ & $132^{* *}$ & ,021 & $431^{* *}$ & $359^{* *}$ & 1 \\
\hline & $\mathrm{p}$ &, 000 & ,002 & ,620 & ,000 & ,000 & \\
\hline & $\mathrm{N}$ & 570 & 570 & 570 & 570 & 570 & 570 \\
\hline
\end{tabular}

$* * p<0.01$

Başarı motivasyonu ile eğitim felsefeleri genel değişkeni arasında orta düzeyde pozitif $(r=0,362)$ ve anlamlı bir ilişki tespit edilmiştir. Eğitim felsefesinin alt boyutları arasında başarı motivasyonu ile en yüksek ilişkiye $r=0,431$ korelasyonla ilerlemecilik sahip iken, onu $r=0,359$ ile yeniden kurmacılık takip etmektedir. Daimicilik $(r=0,132)$ ve esasicilik $(r=0,021)$ başarı motivasyonu ile pozitif yönlü düşük ilişkiye sahiptir. Esasicilik hariç diğer alt boyutların başarı motivasyonu ile ilişkileri anlamlı düzeydedir. Eğitim felsefesi ile alt boyutları arasında pozitif yönlü yüksek sayılabilecek, anlamlı ilişkiler gözlenmiştir. Yeniden kurmacılık $r=0,719$ gibi büyük bir korelasyon katsayısıyla en yüksek ilişkiye sahipken onu daimicilik $(r=0,611)$, esasicilik $(r=0,603)$ ve ilerlemecilik $(r=0,575)$ takip etmiştir. Eğitim felsefesinin alt boyutlarının kendi aralarındaki ilişkilere bakıldığında ise, ilerlemecilik ve yeniden kurmacılık arasında $r=0,642$ korelasyon ile yüksek ilişki gözlenmiştir. Daimicilik ile esasicilik arasındaki korelasyon ise $r=0,572$ bulunmuştur. Diğer değişkenler arası ilişkiler düşük sayılabilecek düzeyde gerçekleşmiştir. Daimicilik ile yeniden kurmacılık arasındaki $r=0,006$ korelasyonu, bu değişkenlerin bağımsız olduklarını kuvvetli olarak işaret etmektedir. Illermecilik ile esasicilik arasındaki $r=-0,135$ korelasyonu düşük sayılabilecek düzeyde ters yönlü ilişkiyi işaret etmektedir. 
Tablo 2

Başarı Motivasyonu ve Eğitim Felsefeleri Arasındaki Regresyon Tablosu

\begin{tabular}{|c|c|c|c|c|c|c|c|c|c|}
\hline \multirow{2}{*}{\multicolumn{2}{|c|}{ Değişken }} & \multicolumn{3}{|c|}{ Standart } & \multirow[b]{2}{*}{ 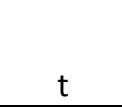 } & \multirow[b]{2}{*}{$p$} & \multirow{2}{*}{$\begin{array}{c}\text { İkili } \\
r\end{array}$} & \multicolumn{2}{|l|}{ Kısmi } \\
\hline & & B & hata & $\beta$ & & & & $\mathrm{R}$ & VIF \\
\hline \multirow[t]{5}{*}{1} & (Sabit) & 2,329 & 155 & & 15,018 & ,000 & & & \\
\hline & EFdai & ,093 & ,034 & 128 & 2,785 & ,006 & 132 & 116, & 1,503 \\
\hline & EFesa &,- 013 & ,029 &,- 022 &,- 451 & 652 & 021 &,- 019 & 1,634 \\
\hline & EFiler & 268 & 039 & 349 & 6,819 & 000 & ,431 & 276 & 1,875 \\
\hline & EFykur & 087 & ,036 & 122 & 2,402 & 017 & 359 & 101 & 1,861 \\
\hline
\end{tabular}

a. Bağımlı değişken (yordanan): Başarı motivasyonu

$R=0.459, R^{2}=0.211, F_{(4,565)}=37.761, p=0.000$, Durbin-Watson (D.W.) İstatistiğ $i=1.915$

Regresyon sonuçlarına bakıldığında; $R^{2}=0,211$ modelin verileri açıklama düzeyini göstermektedir ve başarı motivasyonundaki toplam varyansın \%21,1'inin eğitim felsefesinin alt boyutları tarafından açıklandığına işaret etmektedir. $F$ değeri (37.761) ve $p=0,000$ önem düzeyi determinasyon katsayısı $\mathrm{R}^{2 \prime}$ nin anlamlı olduğunu göstermektedir. Modelde ordinal düzeyde ölçülen değişkenlerin fazlalığına göre, $R^{2 \prime}$ nin kabul edilebilir düzeyde olduğu söylenebilir. Standartlaştırılmış katsayılara göre bağımlı değişken üzerinde ilerlemecilik $r=0,349$ ile en yüksek etkiye sahip iken, daimicilik $r=0,128$ ile ikinci ve yeniden kurmacılık $r=0,122$ ile üçüncü en yüksek etkiye sahiptir. Esasicilik değişkeni ise $r=-0,022$ negatif yönlü olarak en düşük etkiyi göstermiştir. Regresyon katsayılarının anlamlılığına ilişkin t-testi sonuçları incelendiğinde, öğretmen adaylarının başarı odaklı motivasyon puanları üzerinde sırasıyla daimicilik, ilerlemecilik ve yeniden kurmacılığın anlamlı bir yordayıcı olduğu görülmektedir. Esasicilik ise önemli bir etkiye sahip değildir. Varyans şişiren faktör (VIF) değerlerine bakıldığında, hepsi 5 'ten küçük değerler aldığından, farklı varyans görülmediği rahatlıkla söylenebilir. Ardışık bağımlılık (otokorelasyon) için $D_{L}=1,633$ ve $D_{U}=1,715$ olduğundan Durbin-Watson test istatistiği, D.W.=1,915 ile modelde otokorelasyon gözlenmediğini göstermektedir.

Yordayıcı değişkenlerle bağımlı değişken arasındaki ilişkinin doğrusal olup olmadığı ve puanların normal dağılım gösterip göstermediklerini incelemek için oluşturulan histogram aşă̆ıda verilmiştir. 


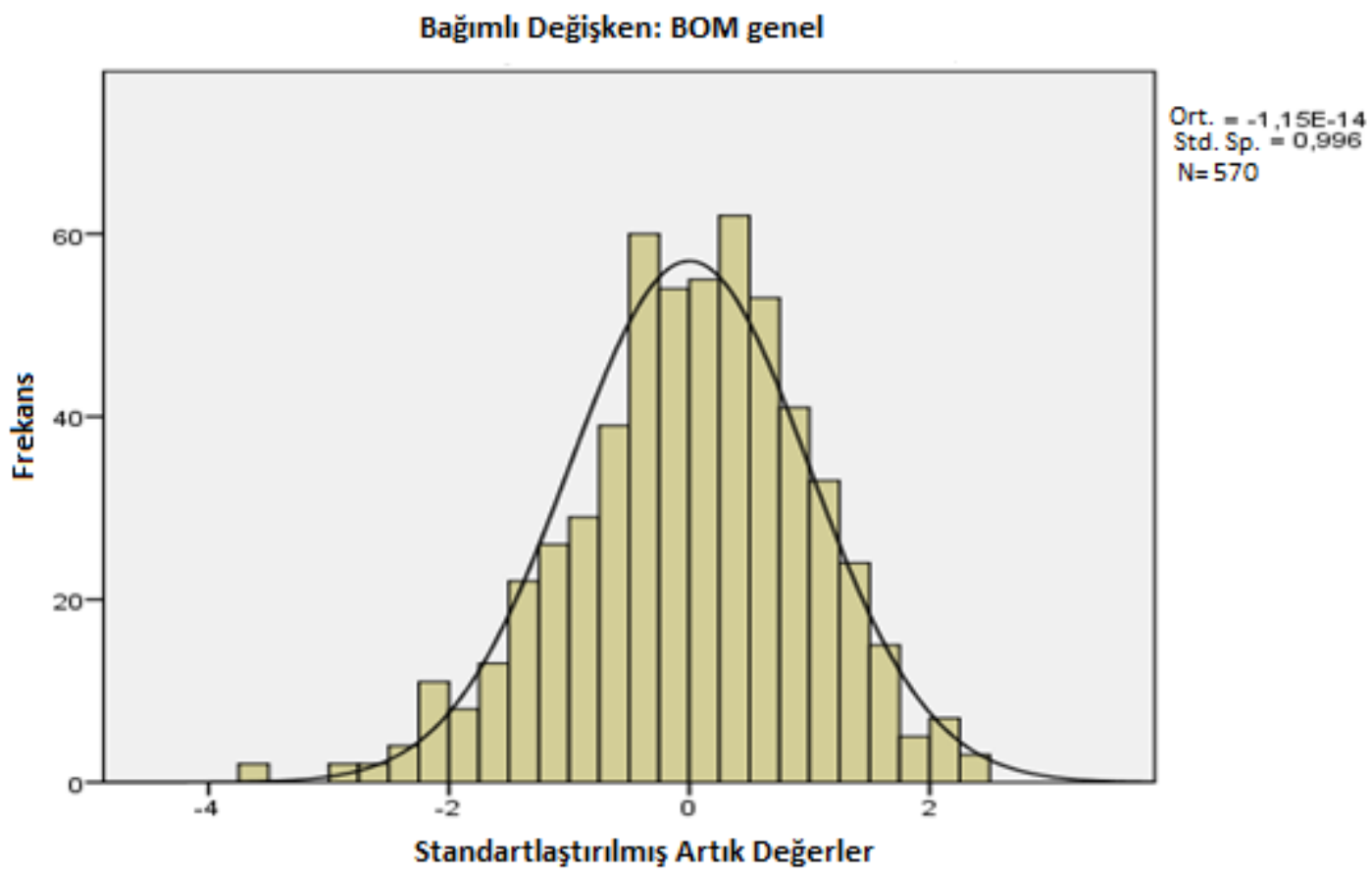

Şekil 1. Standartlaştırılmış artıkların frekans histogramı

Standartlaştırılmış artıkların frekans histogramına bakıldığında, sapmaların 0 etrafında toplandığı ve dağılımın normal dağılıma yakın bir dağılım gösterdiği söylenebilir. Dolayısıyla, regresyon modelinde hata teriminin 0 ortalamalı normal dağılıma sahip olduğu söylenebilir. Standartlaştırılmış artık değerler ile yordanan değerler arasındaki ilişkiyi gözlemlemek için oluşturulan saçılma diyagramı aşağıda verilmiştir.

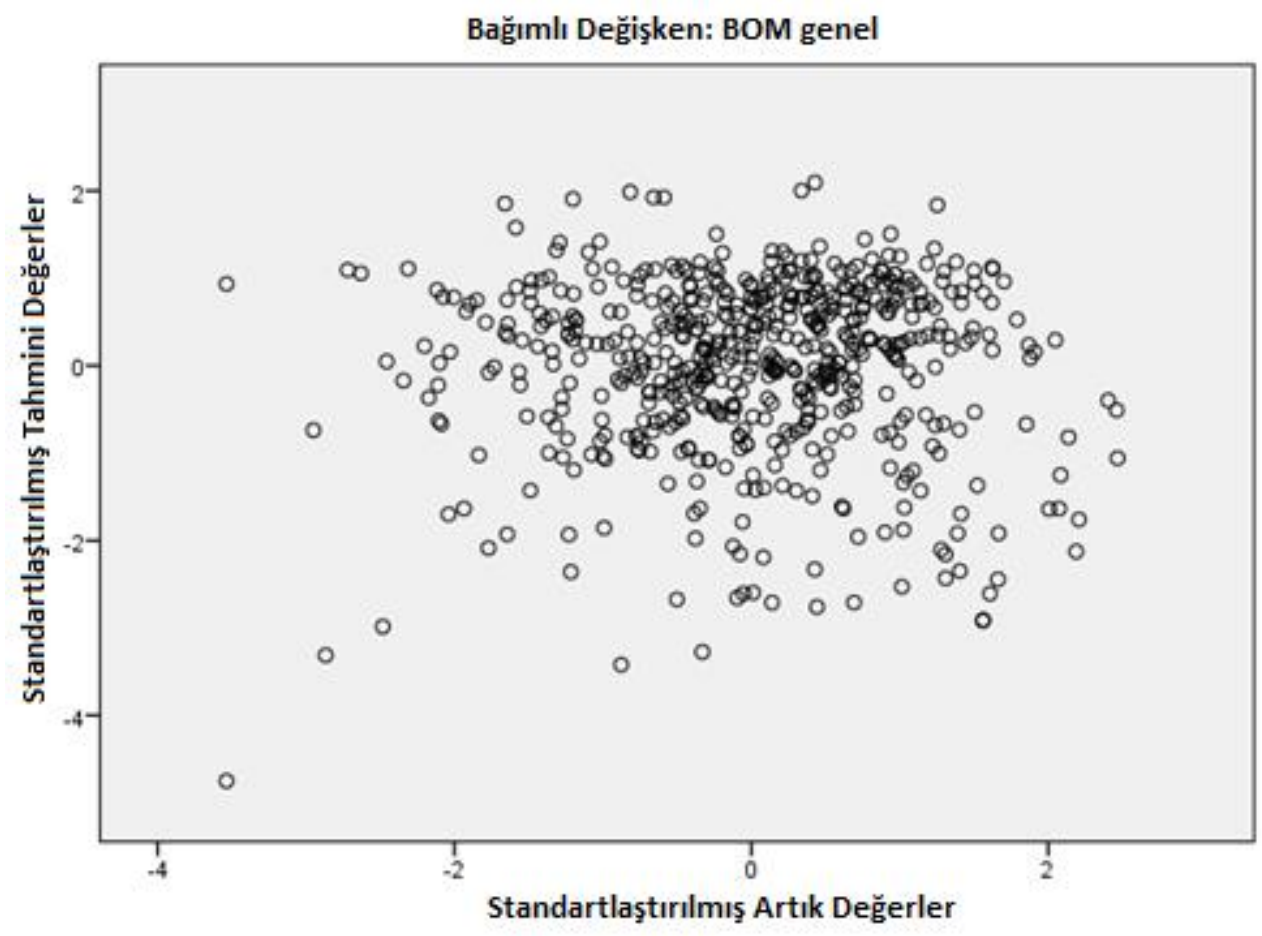

Şekil 2. Regresyon hata teriminin standartlaştırılmış değerlerine ilişkin saçılım grafiği 
Regresyon hata teriminin standartlaştırılmış değerlerinin saçılım grafiğine göre sapmaların büyük çoğunluğunun 0 etrafında simetriğe yakın bir saçıım gösterdiği görülmektedir. Hata teriminin 0 ortalamalı normal dağılımda olduğu ve regresyon modeli için bu varsayımı sağladığı söylenebilir.

Regresyon analizi sonuçlarına göre başarı motivasyonunun yordanmasına ilişkin regresyon eşitliği (matematiksel model) aşağıda verilmiştir.

Başarı motivasyonu $=2,329+0,093 \times \mathrm{EF}$ daimicilik - 0,013 x EF esasicilik $+0,268 \times \mathrm{EF}$ ilerlemecilik $+0,087 \times \mathrm{EF}$ yeniden kurmacilık.

\section{SONUÇ}

Eğitime hedefler sunan, eğitim anlayışının oluşması ve uygulanmasında temel dayanaklardan biri olan eğitim felsefesi ile eğitim-öğretim sürecinde önemli değişkenlerden biri olan başarı motivasyonu arasındaki ilişki ve bu ilişkinin hangi yönde olduğunun bilinmesi öncelikle benimsenen eğitim anlayışının ve bu anlayışın yansıması olan uygulamaların öğrencilerin başarı motivasyonları üzerinde nasıl bir etkiye sahip olduğunun tespit edilmesi açısından önemlidir. Ancak, gerek ulusal gerekse uluslararası alan yazında bu iki değişken arasındaki ilişkiyi inceleyen çalışmaya rastlanmamıştır. Bu durum çalışmada ulaşılan sonuçları daha da değerli kılmaktadır.

Başarı motivasyonu ile benimsenen eğitim felsefeleri arasında orta seviyede, pozitif bir ilişki tespit edilmiştir. Bu iki değişken arasında doğrudan bir ilişki kurmak nispeten zor göründüğü için elde edilen korelasyon önemli sayılabilir. Daimicilik ve esasiciliğe oranla daha modern yaklaşımlara sahip olan ilerlemecilik ve yeniden kurmacılığın başarı motivasyonuyla nispeten daha yüksek ve anlamlı ilişkiye sahip olmaları eğitimde modern anlayışın hâkim olması açısından olumlu görülebilir. Eğitim felsefesi genel değişkeni ile alt boyutları arasında beklendiği gibi yüksek düzeyde pozitif ilişki tespit edilmiştir. Aksi durumda, eğitim felsefesini meydana getiren bileşenlerin sorgulanması gerekirdi.

Eğitim felsefelerinin alt boyutlarının başarı motivasyonundaki değişimin yaklaşık \%21'ini açıklıyor olması yukarıda da belirtildiği gibi aralarında doğrudan bir ilişki kurmanın zor olduğu iki değişkenin görece önemli bir ilişkisi olduğuna işaret etmektedir. Yordayıcı değişkenlerin başarı motivasyonu üzerindeki göreli önem sırası ilerlemecilik, daimicilik, yeniden kurmacılık ve esasicilik şeklinde oluşmuştur. Bu durum daimiciliğin yeniden kurmacılıktan daha önde olmasından dolayı korelasyon analizindeki tespitlerle doğru orantılı gibi görünmese de, daimicilik ve yeniden kurmacılığın standartlaştırıımış regresyon katsayıları birbirine oldukça yakındır. Bu nedenle, korelasyon analizindeki sıralamayla çok farklı bir sıranın ortaya çıkmadığı iddia edilebilir. Burada önemli olan modern eğitim felsefelerinin hem korelasyon analizinde hem de regresyon analizinde başarı motivasyonu ile aralarındaki ilişkinin gücü ve anlamlılı̆ı açısından genel olarak klasik felsefelere göre daha ön plana çıkmış olmalarıdır. Bağımsız değişkenlerle başarı motivasyonu arasındaki ilişkinin doğrusal olduğu ve puanların normal dağılım gösterdiği kayda değer diğer bir bulgu olarak not edilmelidir.

Sonuç olarak, eğitim felsefeleri ve başarı motivasyonu eğitimde oldukça önemli yeri olan değişkenlerdir ve bu değişkenler arasında, bu çalışmadan elde edilen verilere göre hatırı 
sayılır bir ilişki mevcuttur. Bu değişkenler arasındaki ilişkiler hem deneysel hem de betimsel çalışmalarla daha detaylı olarak araştırılmalı ve bu konuda alan yazındaki eksiklik tamamlanmaya çalışılmalıdır.

\section{KAYNAKLAR}

Akpınar, B. (2010). Eğitim programları ve öğretim. Ankara: Data.

Ayhan, H. (1997). Eğitim bilimine giriş. İstanbul: Şule Yayınları.

Biçer, B., Er, H. ve Özel A. (2013). Öğretmen adaylarının epistemolojik inançları ve benimsedikleri eğitim felsefeleri arasındaki ilişki. Eğitimde Kuram ve Uygulama, 9(3), 229-242.

Conti, G. J. (2007). Identifying your educational philosophy: Development of the philosophies held by instructors of lifelong-learners (PHIL). MPAEA Journal of Adult Education Volume 36(1), p.19-37.

Curwin, R. L. (2014). Can assessments motivate. Educational Leadership, 72(1), 38-40.

Duman, B. (2008). Öğrencilerin benimsedikleri eğitim felsefeleriyle kullandıkları öğrenme stratejileri ve öğrenme stillerinin karşılaştırılması. Ç.Ü. Sosyal Bilimler Enstitüsü Dergisi, 17(1), 203-224.

Guthrie, J. T., Wigfield, A., \& VonSecker, C. (2000). Effects of integrated instruction on motivation and strategy use in reading. Journal of Educational Psychology, 92(2), 331341.

Kaplan, L.S. and Owings, W. A. (2015). Educational foundations. Stamford: Cengage Learning.

Kaur, S. (2013). Academic achievement in relation to achievement motivation of high school students. International Journal of Science and Research, 2(12), 409-411.

Moss, G. and Lee, C. (2010). A critical analysis of philosophies of education and INTASC standards in teacher preparation. International Journal of Critical Pedagogy, Vol 3 (2) pp. 36-46.

Sahu, B. (2002). The new educational philosophy. New Delhi: Sarup\&Sons.

Schunk, D.H. (2012). Learning theories: An educational perspective. ( $6^{\text {th }}$ edition). Boston: Pearson Education.

Semerci, Ç., Semerci, N. ve Çerçi, N. (2002). Eğitim-öğretim felsefesini belirleme ölçeği, XI. Eğitim Bilimleri Kongresi, 23-26 Ekim 2002, Yakın Doğu Üniversitesi, Lefkoşa, KKTC.

Semerci, Ç. (2010). Başarı odaklı motivasyon (BOM) ölçeğinin geliştirilmesi. E-Journal of New World Sciences Academy, 5(4), 2123-2133.

Semerci, Ç., Semerci, N. ve Yılmaz, E. (2016). Öğretmen adaylarının eğitim-öğretime ilişkin felsefi düşünceleri: boylamsal bir çalışma. III. Eurasian Educational Research Congress, Muğla Sıtkı Koçman University, 331 Mayıs- 3 Haziran, 2016, Muğla, s. 149-152.

Sönmez, V. (2009). Eğitim felsefesi (9. baskı). Ankara: Anı Yayıncılık.

Story, P.A., Hart, J.W., Stasson, M.F. and Mahoney, J.M. (2009). Using two-factor theory of achievement motivation to examine performance-based outcomes and self-regulatory processes. Personality and Individual Differences, 46, 391-395. 
Ülgen, G. (1997). Eğitim psikolojisi. Ankara: Alkım Yayınevi.

Woolfolk, A. (2013). Educational psychology. Upper Saddle River, New Jersey: Pearson.

Yılmaz, E. (2014). Güçlü Yön Temelli Yaklaşımın Yükseköğretimde Ingilizce Dersinde Devam, Akademik Başarı ve Motivasyon Üzerindeki Etkisinin Incelenmesi. Unpublished PhD Thesis. Fırat University, Elazığ.

Youngs, B.B. (1979). Educational philosophy: Why and for whom. Education, 99(4), 355-358. 


\section{SUMMARY}

This study aims to reveal the relationship between achievement motivation and philosophies of education. Essentialism, perennialism, reconstructionism and progressivism are four philosophies of education taken into account in this study. No studies are found in literature trying to find the relationship between achievement motivation and philosophies of education. Therefore, this study aims at filling the gap in this issue and opening up a discussion concerning these two concepts and their predictability.

Relational screening model was used in the study and the sampling of the study consisted of 570 prospective teachers attending a pedagogical formation course at two universities in Turkey in 2016. No sampling method was employed as all the participants were included in the study. The data were collected using two scales. The first of them was educational-instructional philosophies determination scale. It's a five point likert-type scale and the options range from completely disagree (1) to completely agree (5). The scale includes a sum of 47 items; 10 items regarding perennialism, 12 items regarding essentialism, 13 items for progressivism and 12 items for reconstructionism. The second scale used in the study is achievement focused motivation scale consisting of 35 items. Achievement focused motivation scale has four sub-factors; external effect, internal effect, expansion of objective and selfconsciousness. The total variance of the scale was $37.910 \%$. Item total correlations ranged between 0.36-0.58. 49 data pairs were formed and test-retest correlation was 0.977. The correlation between subjects' scores from the two halves of the scale was 0.895 . Cronbach's Alpha coefficient was found 0.896 .

As a result of the analyses carried out in SPSS 22 statistical package programme, a medium level, positive, significant correlation was found between prospective teachers' achievement motivation scores and the philosophies of education they favour. The educational philosophy having the highest correlation with achievement motivation was progressivism followed by reconstructionism, perennialism and essentialism, respectively. As the standardised coefficients suggest, the variable having the highest effect on achievement motivation was progressivism followed by perennialism, reconstructionism and essentialism, respectively.

It was discovered in the study that $21 \%$ of the change in achievement motivation is accounted for by four sub-factors of educational philosophy. This is important as it is quite hard to relate these two variables. It was observed that contemporary philosophies of education more closely correlated with achievement motivation compared to the classical ones. This is important as there is a resistance to implement contemporary philosophies of education in Turkey. The final noteworthy finding of the study was that the relation between educational philosophies and achievement motivation is linear and the scores are distributed normally.

To conclude, educational philosophies and achievement motivation are two important concepts in education and as the findings of this study suggest there is a considerable relation between the two. The relations between these two constructs should be researched using both experimental and descriptive studies and the lack of knowledge in this subject should be compensated. 